\title{
Barriers and bridges to the adoption of biodegradable plastic mulches for US specialty crop production
}

\author{
Jessica R. Goldberger ${ }^{1, \star}$, Robert Emmet Jones ${ }^{2}$, Carol A. Miles ${ }^{3}$, Russell W. Wallace ${ }^{4}$ \\ and Debra A. Inglis ${ }^{5}$ \\ ${ }^{1}$ Department of Crop and Soil Sciences, Washington State University, Pullman, WA, USA. \\ ${ }^{2}$ Department of Sociology, University of Tennessee, Knoxville, TN, USA. \\ ${ }^{3}$ Department of Horticulture, Washington State University, Northwestern Washington Research and Extension \\ Center, Mount Vernon, WA, USA. \\ ${ }^{4}$ Department of Horticultural Sciences, Texas A\&M AgriLife Research and Extension Center, Lubbock, TX, USA. \\ ${ }^{5}$ Department of Plant Pathology, Washington State University, Northwestern Washington Research and \\ Extension Center, Mount Vernon, WA, USA. \\ ${ }^{*}$ Corresponding author: jgoldberger@wsu.edu
}

\begin{abstract}
Commercial farmers have been using polyethylene plastic mulch since the 1950s. Despite the affordability and effectiveness of polyethylene mulch, the disposal process is financially and environmentally costly. Biodegradable plastic mulches, an ecologically sustainable alternative to polyethylene mulch films, were introduced in the 1980s. Biodegradable plastic mulches can be tilled into the soil or composted at the end of the season, reducing the labor and environmental costs associated with plastic removal and disposal. However, research results are mixed as to the effectiveness, degradability and ease-of-use of biodegradable plastic mulches. In 2008-2012, researchers, funded by a USDA Specialty Crop Research Initiative grant, conducted surveys and focus groups in three different agricultural regions of the USA to better understand the barriers and bridges to the adoption of biodegradable plastic mulches for specialty crop production systems. Data on the experiences and views of specialty crop growers, agricultural extension agents, agricultural input suppliers, mulch manufacturers and other stakeholders showed that the major adoption barriers were insufficient knowledge, high cost and unpredictable breakdown. The major bridges to adoption were reduced waste, environmental benefits and interest in further learning. These findings are discussed with reference to the classic innovation diffusion model, specifically work on the innovation-decision process and the attributes of innovations. The study results can be used to guide the activities of those involved in the design, development and promotion of biodegradable plastic mulches for US specialty crop production systems.
\end{abstract}

Key words: adoption, biodegradable mulch, diffusion, plasticulture, sustainable agriculture, specialty crop production, waste stream

\section{Introduction}

Commercial vegetable and fruit growers use mulch to control weeds, conserve soil moisture, protect crops from contamination by soil, modify soil temperature, minimize nutrient leaching, reduce insect damage, improve plant growth, accelerate crop maturity, enhance produce quality and increase crop yield ${ }^{1-4}$. Polyethylene plastic mulch films, introduced in the 1950s, are the preferred type of mulch among growers of specialty crops (e.g., vegetables and fruits) because of their widespread availability, cost efficient weed control, ease of mechanical application, labor savings, high durability and ability to increase crop yields ${ }^{5-7}$. Polyethylene mulch is made from non-renewable, petroleum-based feedstock, and used typically for one growing season prior to disposal ${ }^{2}$. US vegetable growers use approximately 130 million kilograms (143,000tons) of plastic mulch annually ${ }^{8}$. Despite the affordability and effectiveness of polyethylene mulch, the disposal process is financially and environmentally costly ${ }^{1,3,4,9}$. Removal and disposal costs are often more than $\$ 250$ per hectare $(\$ 100 \text { per acre })^{10}$. Used plastic mulch is typically burned, buried or dumped in landfills $s^{3,9,11}$. Recycling of agricultural plastics is not 
common because of dirt and chemical residues, lack of specialized baling equipment, limited recycling programs, long distances to recycling facilities and high $\operatorname{cost}^{2,9,11,12}$.

Biodegradable plastic agricultural mulches (hereafter biodegradable mulches) were introduced in the 1980s as an ecologically sustainable alternative to polyethylene plastic mulch. Biodegradable mulches can be tilled into the soil or composted at the end of the season, reducing the labor and environmental costs associated with plastic removal and disposal. Biodegradable mulches fall into two major categories based on their primary polymeric constituents: biobased polymers (e.g., starch and cellulose) and synthetic polymers (e.g., polyesters such as polylactic acid $)^{13}$. Commercially available polymers and polymer blends currently employed in biodegradable agricultural mulches include, but are not limited to, Biomax TPS (DuPont, USA), Biopar (Biop, Germany), Biosafe ${ }^{\mathrm{TM}}$ (Xinfu Pharmaceutical Company, China), Eastar Bio ${ }^{\mathrm{TM}}$ (Novamont, Italy), Eco-Flex ${ }^{\circledR}$ (BASF, Germany), Ingeo ${ }^{\circledR}$ (NatureWorks, USA), Mater-Bi ${ }^{\circledR}$ (Novamont, Italy), and Paragon (Avebe, Netherlands) ${ }^{13}$. The degradation of biodegradable mulches results from the action of naturally occurring microorganisms such as bacteria, fungi and algae ${ }^{13-15}$. The rate of biodegradation is influenced by the properties of the mulch materials (e.g., morphology, tensile strength and flexibility, and chemical composition), environmental conditions (e.g., temperature, $\mathrm{pH}$, soil moisture and ultraviolet radiation), and the characteristics of microorganisms capable of biodegradation ${ }^{1,13}$.

New types of biodegradable mulches are continuously being developed and evaluated by scientists and researchers ${ }^{1,2,13,16}$. Field studies have evaluated the performance of numerous types of mulch products ${ }^{2,10,17-22}$. Research results are mixed as to the effectiveness, degradability and ease-of-use of biodegradable mulches ${ }^{2,10,23-25}$. Moreover, lack of consensus among mulch manufacturers and specialty crop growers has surrounded the definitions of 'degradable' and 'biodegradable'. Such findings in part explain why biodegradable mulches constitute a relatively small share of the commercial mulch market ${ }^{1}$. On a more positive note, although more expensive to purchase than polyethylene plastic mulch, biodegradable mulches may be considerably cheaper when the costs associated with removal and disposal are taken into account ${ }^{21,26-28}$.

Another reason for the low adoption of biodegradable mulches to date is that USDA certified organic growers are forbidden to use biodegradable mulch products. According to the current US National Organic Program (NOP) rules, certified organic growers are allowed to use polyethylene plastic as a mulch if the plastic is removed at the end of the growing season. In contrast, organic growers are not allowed to use biodegradable plastic mulch products because the products do not conform to NOP standards ${ }^{29}$. The National Organic Standards Board (NOSB), however, passed a motion in 2012 to recommend the allowance of 'biodegradable biobased mulch films' that are 'produced without organisms or feedstock derived from excluded methods' (e.g., genetically modified organisms) and 'completely biodegradable' (defined as at least $90 \%$ biodegradation in soil within 2 years) ${ }^{30}$. The NOSB sees the allowance of biodegradable biobased mulch films as 'an opportunity to reduce pollution substantially without sacrificing organic farming principles ${ }^{30}$. The anticipated inclusion of biodegradable biobased mulches in the NOP's National List of Allowed and Prohibited Substances (under section \$205.601(b)(2): Synthetic substances allowed for use in organic crop production - as herbicides, weed barriers, as applicable - mulches), and the subsequent potential adoption of biodegradable mulches by a new group of specialty crop growers (i.e., certified organic vegetable and fruit growers), is reason to explore stakeholders' experiences with and perceptions of these new products. Learning from past and current adopters (as well as nonadopters) can aid future diffusion and adoption efforts.

Sociological research is needed to complement the growing number of field studies on the performance of biodegradable mulches. To our knowledge, there are no published comprehensive sociological or related studies that explore stakeholders' experiences with and perceptions of biodegradable mulches. To remedy this situation, we conducted surveys and focus groups to explore the barriers and bridges to the adoption of biodegradable mulches for US specialty crop production. 'Barriers and bridges' are the biophysical, social, cultural, economic or technical factors that may significantly hinder or help, respectively, the successful design, development, diffusion and adoption of an innovation. We obtained information from producers of specialty crops (e.g., vegetables and fruits) as well as other individuals (e.g., agricultural extension agents, agricultural input suppliers, mulch manufacturers and university scientists) involved in the development, diffusion and/or use of biodegradable mulches. This sociological research was part of a large USDA Specialty Crop Research Initiative (SCRI) project entitled 'Biodegradable Mulches for Specialty Crops Produced under Protective Covers.' The SCRI project focused on three growing regions-Mid-South (Knoxville, TN), High Plains (Lubbock, TX), and Pacific Northwest (Mount Vernon, WA) - that were selected because they differ in climate and agricultural production methods, and have been conspicuously underserved, to date, by research and outreach on plasticulture.

In our discussion of the barriers and bridges to the adoption of biodegradable mulches, we draw on the concept of the 'innovation-decision process' ${ }^{31}$. Innovation adoption is not an 'instantaneous act' but rather a process that occurs over time ${ }^{31-33}$. The widely accepted model of the innovation-decision process consists of five stages: knowledge, persuasion, decision, implementation and confirmation (Fig. 1). Active promoters of an innovation (e.g., a new biodegradable mulch product) want targeted individuals (e.g., specialty crop growers) to move seamlessly from initial awareness to final confirmation. 
Table 1. Five attributes of innovations that influence adoption rates.

\begin{tabular}{ll}
\hline Attribute & Description \\
\hline Relative advantage & $\begin{array}{l}\text { Degree to which an innovation is perceived as better (e.g., cheaper and higher status) than an } \\
\text { existing practice or idea } \\
\text { Degree to which an innovation is perceived as consistent with existing values, past experiences and needs } \\
\text { Compatibility }\end{array}$ \\
$\begin{array}{l}\text { Degree to which an innovation is perceived as difficult to understand and use } \\
\text { Trialability }\end{array}$ & $\begin{array}{l}\text { Degree to which an innovation can be experimented with on a limited basis } \\
\text { Observability }\end{array}$ \\
\hline
\end{tabular}

Source: Rogers 2003.

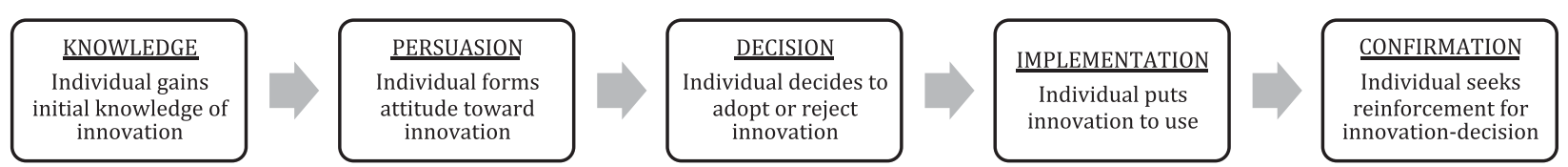

Figure 1. Five stages of the innovation-decision process (source: Rogers 2003).

However, potential adopters may reject an innovation at any stage of the innovation-decision process. For example, a specialty crop grower might learn about a biodegradable mulch product and reject it outright because it does not fit within their existing farming system, whereas another grower might use the new product and then reject it because of problems encountered during the growing season. Our study seeks to determine where individuals are situated in relation to the five-stage innovation-decision process (Fig. 1) with regard to biodegradable mulches. We believe that future design, development and promotion activities could draw on this information to help potential adopters move more quickly through the five stages.

Our study also draws on diffusion of innovations research on how the attributes of innovations influence rates of adoption ${ }^{31,33-37}$. Research has shown that five innovation characteristics are particularly important as predictors of adoption behavior: relative advantage, compatibility, complexity, trialability and observability (Table 1). The emphasis here is on individuals' perceptions of innovation attributes ${ }^{31}$. Innovations that are perceived to be better than other practices, compatible with existing values and needs, easy to understand and use, divisible for small-scale trial, and readily visible tend to be adopted more quickly. Individuals' perceptions of innovation attributes are shaped by socio-institutional relationships $^{31,38}$. For example, a vegetable grower's perceptions of a biodegradable mulch product may be influenced by ties to other growers, local agricultural extension agents, crop consultants and agricultural input suppliers. It is important for promoters of innovations (e.g., new biodegradable mulch products) to understand how stakeholders' perceptions of the five attributes listed in Table 1 can serve as barriers or bridges to adoption.

In sum, the questions addressed in this research are: (1) with regard to biodegradable mulches, where are individuals situated in relation to the five-stage innovation-decision process? (2) What are stakeholders' perceptions of biodegradable mulches and how do these perceptions influence adoption behavior? (3) What are the primary barriers and bridges to the adoption of biodegradable mulches for US specialty crop production?

\section{Methods}

Two surveys and six focus groups were conducted over a 4-year period (2008-2012) in Tennessee, Texas and Washington to explore the barriers and bridges to the adoption of biodegradable mulches for specialty crop production. The first survey (hereafter referred to as the key informant survey) targeted farmers identified by project team members as leaders in using or experimenting with innovative agricultural technologies (e.g., biodegradable mulches, high tunnels) in their respective states. Approximately 15 farmers per state were contacted personally in November/December 2008 and invited to participate in the survey. Only farmers who agreed to participate $(N=41)$ were sent a five-page questionnaire. The survey included questions about experiences with and opinions about biodegradable mulches, as well as farm characteristics. In the survey, biodegradable plastic mulch was defined as a 'manufactured alternative to plastic mulch [that] ideally provides the same benefits of plastic mulch (weed control, soil temperature moderation, and soil moisture conservation) and provides the added benefit of being $100 \%$ biodegradable, either in the field or in composting'. Thirty-four individuals completed the survey for an $85 \%$ response rate.

Six focus groups (two per state) took place during 2010 2011, and included farmers, mulch manufacturers, agricultural extension agents, university scientists and other stakeholders. Each focus group was preceded by a field tour and demonstration of biodegradable mulches and high tunnels at each focus group site. The primary 
objectives of the focus group discussions were to: (1) gauge general knowledge of, interest in and support for biodegradable mulches and (2) identify potential barriers and bridges to the successful design, development and adoption of biodegradable mulches. Eighty individuals were invited to participate in the focus groups; 61 individuals $(76 \%)$ attended. Ninety-five percent of focus group participants filled out a short questionnaire at the end of their respective focus group sessions.

The final survey (hereafter referred to as the intermediary survey) targeted agriculture extension agents, agricultural input suppliers, crop consultants and other individuals who make production recommendations to specialty crop growers in Tennessee, Texas and Washington. Following the Tailored Design Method ${ }^{39}$, 398 individuals were contacted five times by electronic and postal mail in May/June 2012. Individuals were asked to complete an eight-page questionnaire entitled 'Biodegradable Plastic Mulches: Experiences and Opinions of Intermediaries'. A link to an online version of the survey was provided in each mailing. The survey included questions about knowledge/use of plastic mulch, knowledge/use of biodegradable plastic mulch and respondent characteristics. In the survey, biodegradable plastic mulch was defined as a 'plastic mulch product (used to suppress weeds and conserve water) that degrades in the field or in composting'. Eighty-nine individuals were excluded from the study because of ineligibility (e.g., individuals who indicated they did not provide production-related advice to specialty crop growers) and four were excluded for invalid addresses. Ninety-seven individuals completed the survey for an adjusted response rate of $32 \%$.

In total, 192 individuals across three states participated in the surveys and focus groups (Table 2). More study participants were from Tennessee $(N=75)$ and Washington $(N=76)$ than from Texas $(N=41)$. The findings presented below draw on the combined results from the surveys and focus groups. Because of low sample sizes at the state level, we focus primarily on aggregated results across the three states rather than regional differences. However, state location is provided for all direct quotes.

\section{Findings}

\section{Respondent characteristics and experience with biodegradable plastic mulches}

Key informant survey participants, on average, farmed 146 acres and had 24 years of farming experience. Total annual farm receipts ranged from under US $\$ 50,000$ $(34 \%)$ to US $\$ 50,000-499,999(34 \%)$ to US $\$ 500,000$ or more $(32 \%)$. Only $2 \%$ of key informants were actively using biodegradable mulch products on their farms; however, $29 \%$ had used these products in the past, mostly for tomato production. Of the key informants who had used biodegradable mulches, $60 \%$ were not at all satisfied
Table 2. Study participants, 2008-2012.

\begin{tabular}{lcccr}
\hline & Tennessee & Texas & Washington & Total \\
\hline $\begin{array}{c}\text { Key informant } \\
\text { survey (2008) }\end{array}$ & 9 & 11 & 14 & 34 \\
$\begin{array}{c}\text { Focus groups } \\
\quad(2010-2011)\end{array}$ & 20 & 18 & 23 & 61 \\
$\begin{array}{c}\text { Intermediary } \\
\text { survey (2012) }\end{array}$ & 46 & 12 & 39 & 97 \\
Total & 75 & 41 & 76 & 192 \\
\hline
\end{tabular}

with the results, $10 \%$ were somewhat satisfied, $10 \%$ were very satisfied and $20 \%$ were unsure.

Most $(73 \%)$ of the intermediary survey participants worked in university extension, whereas smaller percentages worked as crop consultants, farm supply store managers, farm planners and conservation district administrators. The intermediaries had, on average, 15 years of experience providing production-related advice to specialty crop growers; $75 \%$ of intermediaries specialized in vegetable production. Although $64 \%$ of intermediaries were familiar with biodegradable mulches, only $25 \%$ stated that they 'occasionally' or 'often' recommended the use of biodegradable mulches. Twenty-three percent indicated that growers in their area or state 'occasionally' or 'often' asked about biodegradable mulches. On average, the intermediaries estimated that $7 \%$ of specialty crop growers in their respective regions used biodegradable mulches. Of the intermediaries who were familiar with biodegradable mulches, $9 \%$ were not satisfied with the results, $32 \%$ were somewhat satisfied, $9 \%$ were very satisfied and $50 \%$ were unsure.

Detailed information about farming experience, operation size, agency affiliation and prior use of biodegradable mulches was not collected for every focus group participant, so we are unable to present aggregated results here. It was clear from the focus group discussions, however, that very few individuals had firsthand experience with biodegradable mulches.

\section{Perceived barriers to the adoption of biodegradable plastic mulches}

Insufficient knowledge. Lack of information about an innovation can prevent individuals from moving through the stages of the innovation-decision process ${ }^{31}$. Our survey and focus group results suggest that many farmers, agricultural extension agents, agricultural input suppliers, and other individuals who could potentially use or recommend biodegradable mulches in specialty crop production systems lack sufficient knowledge to move from the knowledge and persuasion stages to the decision, implementation and confirmation stages of the innovation-decision process (see Fig. 1).

Most key informant survey participants lacked sufficient information about biodegradable mulches. 
Table 3. Perceptions of potential problems related to the use of biodegradable plastic mulches, key informant survey results, 2008.

\begin{tabular}{|c|c|c|c|c|c|}
\hline Potential problem & $\begin{array}{l}\text { Not a } \\
\text { problem }(\%)\end{array}$ & $\begin{array}{l}\text { Minor } \\
\text { problem }(\%)\end{array}$ & $\begin{array}{c}\text { Moderate } \\
\text { problem }(\%)\end{array}$ & $\begin{array}{c}\text { Serious } \\
\text { problem }(\%)\end{array}$ & $\begin{array}{c}\text { Don't } \\
\text { know }(\%)\end{array}$ \\
\hline $\begin{array}{l}\text { I do not have enough information about biodegradable } \\
\text { mulches }\end{array}$ & 5.9 & 5.9 & 35.3 & 32.4 & 20.6 \\
\hline High cost of biodegradable mulches & 2.9 & 8.8 & 14.7 & 32.4 & 41.2 \\
\hline $\begin{array}{l}\text { I am unsure about the release of potentially toxic by-products } \\
\text { into the soil or air }\end{array}$ & 11.8 & 8.8 & 17.6 & 20.6 & 41.2 \\
\hline $\begin{array}{l}\text { I am unsure of the impact on my soil, including beneficial } \\
\text { and pathogenic organisms }\end{array}$ & 11.8 & 2.9 & 11.8 & 20.6 & 52.9 \\
\hline I do not have the equipment to lay biodegradable mulch & 29.4 & 14.7 & 5.9 & 20.6 & 29.4 \\
\hline $\begin{array}{l}\text { Don't know enough about how to effectively use } \\
\text { biodegradable mulches }\end{array}$ & 17.6 & 14.7 & 26.5 & 17.6 & 23.5 \\
\hline $\begin{array}{l}\text { Biodegradable mulches do not control weeds well or long } \\
\text { enough through the season }\end{array}$ & 5.9 & 0.0 & 8.8 & 17.6 & 67.6 \\
\hline High cost of disposal of biodegradable mulches & 29.4 & 5.9 & 5.9 & 17.6 & 41.2 \\
\hline I do not believe these products are totally biodegradable & 0.0 & 14.7 & 14.7 & 14.7 & 55.9 \\
\hline $\begin{array}{l}\text { Biodegradable mulches have too loose a fit on the } \\
\text { bed or tear during laying }\end{array}$ & 0.0 & 2.9 & 8.8 & 14.7 & 73.5 \\
\hline $\begin{array}{l}\text { I am unable to transport biodegradable mulch to a local } \\
\text { site for composting }\end{array}$ & 35.3 & 5.9 & 2.9 & 14.7 & 41.2 \\
\hline Biodegradable mulches are not available in my area & 23.5 & 23.5 & 11.8 & 11.8 & 29.4 \\
\hline $\begin{array}{l}\text { I do not have the ability to on-farm compost } \\
\text { biodegradable mulches }\end{array}$ & 29.4 & 17.6 & 5.9 & 8.8 & 38.2 \\
\hline $\begin{array}{l}\text { Soil temperatures are negatively impacted under } \\
\text { biodegradable mulches }\end{array}$ & 14.7 & 11.8 & 2.9 & 8.8 & 61.8 \\
\hline $\begin{array}{l}\text { Biodegradable mulch is not suited to my irrigation } \\
\text { practices/system }\end{array}$ & 38.2 & 5.9 & 0.0 & 8.8 & 47.1 \\
\hline Biodegradable mulch requires too much management & 17.6 & 14.7 & 11.8 & 2.9 & 52.9 \\
\hline Biodegradable mulch is not suited to the crops I grow & 32.4 & 26.5 & 5.9 & 2.9 & 32.4 \\
\hline $\begin{array}{l}\text { Biodegradable mulches are not suited to fumigation } \\
\text { and biofumigation }\end{array}$ & 23.5 & 2.9 & 2.9 & 2.9 & 67.6 \\
\hline
\end{tabular}

$N=34$.

Seventy-eight percent of key informants indicated that they did not have adequate access to biodegradable mulch information. In a different question, respondents were provided with a list of 18 potential problems associated with the use of biodegradable mulches and asked to rate each as 'not a problem', 'minor problem', 'moderate problem', 'serious problem' or 'don't know' (Table 3). Two-thirds $(68 \%)$ of respondents indicated that 'not having enough information about biodegradable mulches' was a moderate or serious problem. Forty-four percent indicated that 'not knowing enough about how to effectively use biodegradable mulches' was a moderate or serious problem. More than $40 \%$ of respondents felt that they did not know enough about biodegradable mulches to provide informed responses for 12 of the 18 potential problems associated with biodegradable mulch use (Table 3).

Focus group participants' knowledge of biodegradable mulches was assessed by examining follow-up survey answers and comments made during focus group discussions. Thirty-five percent of participants indicated that they knew 'very little' about biodegradable mulches before the field tour, demonstration and group discussion.
Participants' comments about insufficient knowledge included:

My knowledge level is zero ... Biodegradable mulchesdidn't know there were such things. (Texas Focus Group 2)

My level of knowledge on biodegradable mulches I would say is fairly low. I've done a little bit of Internet research ... I have tried to work in some different sources of biodegradable mulches, so I'm aware of it. I guess the kraft paper is kind of all I really know about. So I'd say I have a low level of knowledge. (Tennessee Focus Group 2)

I would say that the knowledge base from my experience of knowing a lot of people up and down the coast and in our western region here ... it's very limited. There's no knowledge of biodegradable mulches out there. I don't know if anybody really uses them in a real application. (Washington Focus Group 1)

Focus group participants discussed not only their own lack of knowledge, but also insufficient knowledge among growers in their respective regions.

The intermediary survey participants also lacked sufficient knowledge of biodegradable mulches. Over one-third $(37 \%)$ of intermediaries were 'not familiar', $58 \%$ were 'somewhat familiar' and only $5 \%$ were 
Table 4. Perceptions of potential problems related to the use of biodegradable plastic mulches, intermediary survey results, 2012.

\begin{tabular}{|c|c|c|c|c|c|}
\hline Potential problem & $\begin{array}{c}\text { Not a } \\
\text { problem }(\%)\end{array}$ & $\begin{array}{c}\text { Minor } \\
\text { problem }(\%)\end{array}$ & $\begin{array}{c}\text { Moderate } \\
\text { problem }(\%)\end{array}$ & $\begin{array}{c}\text { Serious } \\
\text { problem }(\%)\end{array}$ & $\begin{array}{c}\text { Don't } \\
\text { know }(\%)\end{array}$ \\
\hline Lack of knowledge about effective biodegradable mulch use & 2.4 & 8.3 & 15.5 & 31.0 & 42.9 \\
\hline Cost of specialized mulch laying equipment & 1.2 & 9.4 & 22.4 & 22.4 & 44.7 \\
\hline Difficulty of maintaining biodegradable mulches in fields & 0.0 & 6.0 & 22.9 & 21.7 & 49.4 \\
\hline Tearing of biodegradable mulches during laying & 0.0 & 4.8 & 25.3 & 20.5 & 49.4 \\
\hline Cost of biodegradable mulches & 0.0 & 4.7 & 27.1 & 20.0 & 48.2 \\
\hline Limited availability of biodegradable mulches & 0.0 & 9.4 & 29.4 & 20.0 & 41.2 \\
\hline Biodegradable mulches do not completely break down & 0.0 & 2.4 & 26.8 & 18.3 & 52.4 \\
\hline Lack of composting options for biodegradable mulches & 1.2 & 4.9 & 22.0 & 15.9 & 56.1 \\
\hline Labor (time/cost) required to lay biodegradable mulches & 1.2 & 18.1 & 21.7 & 9.6 & 49.4 \\
\hline Loose fit of biodegradable mulches on beds & 0.0 & 9.6 & 30.1 & 8.4 & 51.8 \\
\hline Biodegradable mulches are potentially toxic & 1.2 & 14.5 & 10.8 & 7.2 & 66.3 \\
\hline Biodegradable mulches do not control weeds well & 2.4 & 13.3 & 21.7 & 6.0 & 56.6 \\
\hline Biodegradable mulches negatively impact soil moisture & 1.2 & 13.3 & 16.9 & 2.4 & 66.3 \\
\hline Irrigation constraints & 8.3 & 21.4 & 20.2 & 2.4 & 47.6 \\
\hline
\end{tabular}

N's range from 82 to 85 .

'very familiar' with biodegradable mulches. When asked to rate the seriousness of 14 potential problems related to the use of biodegradable mulches by specialty crop growers, many intermediaries did not feel informed enough to provide an answer. The percentage of respondents who selected 'don't know' ranged from 41 to $66 \%$ across the 14 items (Table 4). Moreover, 'lack of knowledge about effective biodegradable plastic mulch use' was perceived by intermediaries to be the most serious problem related to biodegradable mulches for specialty crop growers (Table 4).

Stakeholders' insufficient knowledge may have been related to the perceived complexity associated with selecting and effectively using biodegradable mulches. Perceived complexity is an innovation attribute known to negatively influence adoption rates (Table 1). It is not clear, however, from our survey and focus group results if innovation complexity per se was hindering adoption. It is more likely that stakeholders' insufficient knowledge stemmed from their location in the early stages of the innovation-decision process, rather than from their inability to understand the innovation.

High cost. Participants in both the key informant and intermediary surveys expressed concern about the costs associated with using biodegradable mulches. Approximately one-third of key informants who had used biodegradable mulches in their farming operations stated that high cost was an issue. Nearly half (47\%) of all key informants indicated that 'high cost of biodegradable plastic mulches' was a moderate or serious problem (Table 3). Similarly, $47 \%$ of intermediaries believed that 'cost of biodegradable plastic mulches' was a moderate or serious problem (Table 4). Slightly smaller percentages of intermediaries considered the 'cost of specialized mulch laying equipment' (45\%) and 'labor (time/cost) required to lay biodegradable plastic mulches' $(31 \%)$ to be moderate or serious problems (Table 4). In response to an open-ended question about what they liked least about biodegradable mulches, intermediaries expressed major concerns about the costs of biodegradable mulch products, laying equipment and labor for installation and removal.

The focus group participants were also concerned with the high cost of biodegradable mulches (especially relative to polyethylene plastic mulch), as well as the associated equipment and labor costs. Participants remarked:

The biggest [barrier] for me is cost ... Just initial, when I'm talking about bare ground, and I don't have much mulch experience ... So unless I'm going to see a huge amount coming back to me, the added cost, whether it be biodegradable or any mulch, that's the big deal. (Texas Focus Group 1)

I can see the advantage to a commercial, big time grower that has the [equipment] that lays it out, covers the edges [with] dirt ... But to a small farmer, it's almost cost prohibitive and too labor intensive. (Tennessee Focus Group 1)

One Washington focus group participant remarked that 'everyone would adopt' biodegradable mulch if it was not 'ten times the cost' of conventional plastic mulch. Regardless of the accuracy of the tenfold cost difference, the perception of higher cost is a significant barrier to the adoption of biodegradable mulches. Perceived higher cost, a relative disadvantage, is an innovation attribute correlated with slower adoption rates (Table 1).

Unpredictable breakdown. Key informant survey participants were asked to describe problems they had experienced with regard to using biodegradable mulches. Nearly all key informants who had firsthand experience with using biodegradable mulches mentioned problems related to unpredictable breakdown. Responses ranged from 'disintegrated too quickly' and 'quick decay' to 
'doesn't biodegrade fast enough' and 'never fully degraded.' Forty-five percent of key informants (including individuals who had never used biodegradable mulches) were skeptical that biodegradable mulches were totally biodegradable (Table 3). The intermediary survey produced similar results: $45 \%$ of intermediaries believed 'biodegradable plastic mulches do not completely break down' was a moderate or serious problem (Table 4). In written comments about what they liked least about biodegradable mulches, intermediaries expressed concerns about both fast degradation (e.g., 'breaks down too quickly', 'most do not last the length of time specified' and 'often starts to disintegrate before the production season is over') and slow degradation (e.g., 'unproven complete biodegradability', 'some small pieces don't degrade as fast as I would like' and 'does not degrade in a timely fashion').

Unpredictable breakdown was a major topic of conversation among the focus group participants. Some individuals expressed concern about the loss of biodegradable mulch integrity early in the season. A Tennessee focus group participant commented:

Does [biodegradable mulch] really last through the season? Or am I going to get halfway through the season and my mulch around my tomatoes and planters is gone, and now I've got to deal with those weeds again. (Tennessee Focus Group 2)

Individuals in all three states were concerned about incomplete breakdown at the end of the growing season:

The biodegradable mulch I've been watching for a while, and I've yet to see it degrade in one year... It seems like there's a little carryover. (Texas Focus Group 1)

I've heard lots of people talking about you've got to pick up all this stuff in the fall. Well that doesn't sound like biodegradable to me. (Tennessee Focus Group 1)

We started [agricultural] plastics recycling in our county about three years ago and the person doing that ... said biodegradable mulches just leave smaller particles of plastics in the soil. So we would need proof that this was not the case. (Washington Focus Group 2)

A related concern among focus group participants was the unknown impact of biodegradable mulches on the soil. Some comments related to potentially harmful byproducts:

Well, it might be biodegradable in 500 years and maybe 97 percent of it is gone but the 3 percent that's left is all the bad stuff. (Washington Focus Group 1)

From a soil stewardship perspective I'm less afraid of black plastic than I am of these biodegradable ones ... [With black plastic] I'm confident that I didn't put anything in my soil that's going to come back and haunt me through generations. (Washington Focus Group 2)

My main concern is that there's going to be buildup in the soil ... Once it biodegrades, is there going to be a buildup of something that is going to hinder a future crop? (Tennessee Focus Group 1)
Other focus group participants emphasized the unknown impact on soil organisms:

You know that if you put newspaper down on the ground, the next year that newspaper, you can till it right into the ground without a bit of problem. It's going to be worm food and looking good, you know? It's going to actually build your soil. Is [biodegradable mulch] going to do that? (Tennessee Focus Group 1)

I really hesitate to use [biodegradable] mulch until I know that it's going to be good for the soil, and it will break back down without hurting things. (Tennessee Focus Group 1)

Key informant survey participants were also concerned about the release of potentially toxic by-products into the soil and the impacts of biodegradable mulch use on soil organisms (Table 3 ).

\section{Potential bridges to the adoption of biodegradable plastic mulches}

Reduced waste. The previous section illustrated that the unpredictable breakdown of biodegradable mulches can serve as a significant adoption barrier. However, there is ample evidence from the intermediary survey and focus groups to suggest that biodegradability, in general, can also serve as a bridge to adoption. Complete biodegradability means growers do not need to remove and dispose of agricultural plastics - activities that can be quite laborintensive and expensive. In response to an open-ended question about what they liked the best about biodegradable mulches, approximately $50 \%$ of the intermediaries emphasized biodegradability and not having to remove and dispose of mulch materials. Examples of written comments included: 'not hav[ing] to pull it up at the end of the growing season is very convenient' (Tennessee county extension director), '[it doesn't] have to be removed and disposed of' (Texas horticulture extension agent), 'retrieval and disposal [are] not necessary' (Washington agricultural input supplier), and 'elimination from the waste stream' (Washington farm planner).

Focus group participants also liked that the use of biodegradable mulches ideally eliminates the need for plastic removal and disposal. Here two Washington participants discuss their preference for biodegradable mulches over polyethylene plastic mulches:

I used plastic mulches to some degree for maybe six to eight years. I tried using biodegradable ones [but] I couldn't get it off my roller and it's still sitting in some shed. Ideologically I would love to do that. I hate ... to go out and pick [plastic mulch] up and stuff it in the dumpster. (Washington Focus Group 1)

There's considerable demand, especially for biodegradable mulches because trying to get rid of the black plastic is really problematic ... I think this generation of people that are coming into the workforce don't want to deal with that issue continually. (Washington Focus Group 1) 
A focus group participant in Tennessee put it simply: 'having less plastic in the landfills is a really good thing' (Tennessee Focus Group 2). The association of biodegradable mulches with reduced waste appears to be compatible with stakeholders' ideological orientations and values. Moreover, the 'disappearance' (biodegradability) of new mulch products in the field is a very visible result of using such products. Compatibility and observability are innovation attributes known to be positively correlated with rate of adoption (Table 1).

Environmental benefits. Intermediary survey participants especially liked that biodegradable mulches were environmentally friendly. In written comments about what they liked best about biodegradable mulches, respondents wrote: '[they will] break down therefore [they are] environmentally friendly' (Tennessee county extension director) and 'they break down when left in the environment' (Washington county extension director). A Tennessee county extension agent and a Washington crop consultant simply wrote 'environmentally friendly' as their favorite biodegradable mulch characteristic. Focus group participants also mentioned the environmental benefits of biodegradable mulches:

The advantage to biodegradable mulch is that we're putting less plastics and stuff into the soil ... It's good for the environment. (Tennessee Focus Group 1)

We've used plastic mulches probably about eight to ten years now. And I went to a master gardeners meeting ... I had never heard of biodegradable mulches. I got real excited to hear about it, just because of the benefit to the environment... So I'm really interested in seeing how they compare to the plastic mulches. (Tennessee Focus Group 2)

The fact that some stakeholders perceive biodegradable mulches to be better for the environment than polyethylene plastic mulches is a potentially important bridge to adoption. As Table 1 indicates, innovations with a perceived relative advantage, such as a smaller environmental footprint, are associated with faster rates of adoption.

Interest in further learning. A significant bridge to adoption is the desire on the part of the majority of study participants to learn more about biodegradable mulches. Many individuals appear to be interested in moving from the knowledge stage to the persuasion, decision and implementation stages of the innovation-decision process (see Fig. 1). For example, the key informant survey results indicated that $50 \%$ of respondents were interested in working with scientists and extension educators on research related to improving farming systems using biodegradable mulches.

All of the focus group participants expressed an interest in learning more about biodegradable mulches; $82 \%$ were 'very interested' and $18 \%$ were 'somewhat interested' according to the follow-up survey results. In addition, most focus group participants were 'very interested' (84\%) or 'somewhat interested' (13\%) in working with scientists and agricultural extension agents on biodegradable mulch design, development and dissemination. The desire for more information - whether through attendance at field days, participation in on-farm trials or other types of interactions with scientists and extension agents - was expressed during focus group discussions:

I would rate [biodegradable mulches] as an emerging technology. You know, everybody is really interested and watching it happen in other places ... There's not a lot of acreage yet ... Steep learning curve. I think there's a lot of interest ... It's on an upward curve. (Washington Focus Group 2)

I'm really interested in biodegradable mulches. I've done a tremendous amount of research on the Internet, but have not used them. I've used plastic mulch for one year ... So I'm probably middle of the road as far as knowledge. Not actually having seen it used, even though I've read a lot about it. (Texas Focus Group 1)

Before I started coming to these things, if we were talking about biodegradable mulch, I just barely knew what mulch was. My biodegradable mulch is leaves ... It would be neat to have, you know, a forklift, roll of plastic that was affordable that you just roll out ... punch holes in it, plant stuff in it, and then have that stuff disappear, enrich the soil. That would be fantastic. (Tennessee Focus Group 1)

Intermediary survey participants were also interested in increasing their knowledge of biodegradable mulches. Nearly two-thirds $(64 \%)$ of survey respondents were 'somewhat interested' and 29\% were 'very interested' in learning more about biodegradable mulches. One intermediary expressed a desire to teach other individuals about the innovation: ' $[\mathrm{I}]$ need some biodegradable mulch to try in demonstrations' (Tennessee agricultural extension agent). Another intermediary wanted to experiment with biodegradable mulches for windbreak plantings: 'I have nine plantings with different types of fabrics and would like to find a biodegradable mulch' (Washington conservation district coordinator). These comments illustrate potential adopters' interest in experimenting with biodegradable mulch products on a small scale before deciding to fully adopt them. Such trialability should positively influence adoption rates (Table 1).

The results of the intermediary survey also provide information about recent sources of biodegradable mulch information and preferred information channels. In 2007 2012, the most important sources of biodegradable mulch information for survey respondents were extension educators/specialists, university scientists, field days, extension conferences/workshops and farm tours. The least important sources of information were state-level departments of agriculture, the Natural Resources Conservation Service, formal education and crop consultants. When asked about future biodegradable mulch information channels, a majority of intermediaries across the three states preferred printed materials $(78 \%)$, field days or demonstrations $(78 \%)$, farm tours $(56 \%)$, and Internet or 
e-mail (54\%). In a written comment one survey respondent expressed a specific need for best management practices:

I look forward to best management practices for different mulches. For example, mulch A controls weeds well, but biodegrades slowly and should be removed from the field and composted in a hot pile. Or, mulch B is certified organic, decomposes well, but weed control is below par. (Washington extension specialist)

Results were mixed for in-person workshops, which were preferred by $64 \%$ of Texas respondents, $43 \%$ of Washington respondents and $33 \%$ of Tennessee respondents. Intermediaries in all three states were far less interested in one-on-one consultations, courses (in-person and online), large group meetings (in-person and online) and social media as means for receiving biodegradable mulch information in the future.

\section{Summary and Conclusion}

The first question addressed in our study focused on where individuals (particularly specialty crop growers in agricultural regions that have been underserved by research and outreach on plasticulture) were situated in relation to the five-stage innovation-decision process (Fig. 1). We found that some individuals knew very little about biodegradable mulches (knowledge or pre-knowledge stage), whereas others had used biodegradable mulches or recommended their use to others (implementation or confirmation stage). Most study participants, however, were still forming opinions (persuasion stage) and, consequently, eager to learn more before deciding to adopt or reject biodegradable mulches (decision stage).

We found that insufficient knowledge was a significant barrier to the adoption of biodegradable mulches. Many farmers, agricultural extension agents, agricultural input suppliers and other stakeholders who could potentially use or recommend biodegradable mulches lacked adequate information. Lack of knowledge, however, was not due to the lack of interest. The study participants were very interested in learning more about biodegradable mulches, and they preferred to receive information via printed materials, field days and farm tours. Many study participants also expressed an interest in collaborating with scientists and extension educators on biodegradable mulch research projects. As specialty crop growers are at different stages in the innovation-diffusion process, a 'one size fits all' promotion approach is not appropriate. Sociological research has shown that the effectiveness of different information sources (e.g., university extension and neighbors) and communication channels (e.g., publications, web-based resources and in-person workshops) vary across the five stages of the innovation-decision process. For example, mass media channels may generate awareness of a particular innovation, but face-to-face interactions with experts and early adopters are usually necessary in the later stages of the innovation-decision process to obtain technical information about the innovation $^{31,33,40}$. Our study participants' preference for printed materials, field days and farm tours rather than, for example, social media and one-on-one consultations, reflects their position in the middle of the five-stage innovation-decision process.

Our second research question focused on stakeholders' perceptions of biodegradable mulches and the influence of these perceptions on adoption behavior. Our findings suggest that two perceptions in particular are hindering adoption. First, a significant adoption barrier is the perception that biodegradable mulches cost more than polyethylene plastic mulch. Biodegradable mulches may be more expensive to purchase but appear to be cheaper than conventional plastic mulch when removal, disposal and environmental costs are fully considered ${ }^{21,26,28}$. There is a need for more in-depth research on the economics of biodegradable mulch use and how best to communicate this information to potential adopters. Second, the perception of the unpredictable breakdown of biodegradable mulch products is another significant barrier to adoption. Some study participants expressed concerns about new mulch products degrading too quickly; others were concerned about slow degradation. Stakeholders' experiences and perceptions regarding unpredictable breakdown correspond with findings from field studies where varying degrees of deterioration are the result of product type, site location and other factors ${ }^{2,10,18-22}$. The next generation of biodegradable mulch products should be designed to meet users' expectations of effective performance during the growing season in a variety of environments followed by timely biodegradation in the field or in composting.

Although some perceptions of biodegradable mulches are barriers to adoption, other perceptions can serve as bridges to adoption. Our findings suggest that the perceived environmental benefits and waste stream reduction associated with biodegradable mulches can positively influence adoption behavior. The fact that biodegradable mulches generate little to no plastic waste was highly compatible with study participants' ideological beliefs and values (e.g., the desire to avoid mulch made from nonrenewable feedstock, the desire to not contribute to the agricultural plastics waste stream). Some study participants commented that the landfilling of polyethylene plastic mulch is simply not a sustainable option for US specialty crop production. Study participants also spoke in more general terms about the environmental benefits associated with biodegradable mulches. Biodegradable mulches had a clear perceived relative advantage over polyethylene plastic mulch in terms of environmental footprint. Compatibility and relative advantage are innovation attributes known to positively influence adoption rates (Table 1).

Our final, and overarching, research question was: what are the primary barriers and bridges to the adoption of 
biodegradable mulches for US specialty crop production? As already mentioned, we found that lack of knowledge, high cost and unpredictable breakdown were the primary barriers to the adoption of biodegradable mulches. However, these barriers can be overcome through enhanced stakeholder outreach, further economic studies and the development of more predictable mulch products. The primary bridges to adoption were waste stream and environmental benefits, as well as stakeholders' desire for additional information. Individuals and groups involved in the promotion of biodegradable mulch products should emphasize waste stream and environmental benefits via stakeholders' preferred communication channels, which include printed materials, field days and farm tours.

Our study focused on three different US agricultural regions (Mid-South, High Plains and Pacific Northwest) and relied on sociological methods and concepts. It fills a gap in the literature and complements existing field studies by documenting stakeholders' experiences with and perceptions of biodegradable mulches, a promising ecologically sustainable alternative to polyethylene plastic mulch. Understanding stakeholders' experiences and perceptions is critical for the successful design, development, diffusion and adoption of biodegradable mulches for US specialty crop production systems. As an increasing number of specialty crop growers, including certified organic producers, develop interest in and gain firsthand experience with biodegradable mulches, sociological studies should continue to explore the barriers and bridges to the diffusion and adoption of these products in different growing regions.

Acknowledgements. Funding for this project was provided by a USDA-NIFA Specialty Crop Research Initiative (SCRI) grant for 'Biodegradable Mulches for Specialty Crops Produced Under Protective Covers' (Award no. 2009-51181-05897). The authors thank Annabel Kirschner, Curtis Beus, Andrew Corbin and Annette Wszelaki for their important contributions. Invaluable survey assistance was provided by Rose KrebillPrather and Leona Ding at Washington State University's Social and Economic Sciences Research Center.

\section{References}

1 Kasirajan, S. and Ngouajio, M. 2012. Polyethylene and biodegradable mulches for agricultural applications: A review. Agronomy for Sustainable Development 32:501-529.

2 Miles, C., Wallace, R., Wszelaki, A., Martin, J., Cowan, J., Walters, T., and Inglis, D. 2012. Deterioration of potentially biodegradable alternatives to black plastic mulch in three tomato production regions. Horticultural Science 47 (9):1270-1277.

3 Lamont, W.J. 1993. Plastic mulches for the production of vegetable crops. Horticultural Technology 3(1):35-39.

4 Lamont, W.J. 2005. Plastics: Modifying the microclimate for the production of vegetable crops. Horticultural Technology 15(3):477-481.

5 Hill, D.E., Hankin, L., and Stephens, G.R. 1982. Mulches: Their Effects on Fruit Set, Timing and Yields of Vegetables.
Bulletin 805. The Connecticut Agricultural Experiment Station, New Haven, CT.

6 Schonbeck, M.W. 1995. Mulching Practices and Innovations for Warm Season Vegetables in Virginia and Neighboring States. 1. An Informal Survey of Growers. Virginia Association for Biological Farming, Blacksburg, VA.

7 Schonbeck, M.W. and Evanylo, G.K. 1998. Effects of mulches on soil properties and tomato production. I. Soil temperature, soil moisture and marketable yield. Journal of Sustainable Agriculture 13(1):55-81.

8 Shogren, R.L. and Hochmuth, R.C. 2004. Field evaluation of watermelon grown on paper-polymerized vegetable oil mulches. Horticultural Science 39(7):1588-1591.

9 Hussain, I. and Hamid, H. 2003. Plastics in agriculture. In A.L. Andrady (ed.) Plastics and the Environment. Wiley, Hoboken, NJ. p. 185-209.

10 Shogren, R.L. 2000. Biodegradable mulches from renewable resources. Journal of Sustainable Agriculture 16(4):33-47.

11 Hemphill, D.D. 1993. Agricultural plastics as solid waste: What are the options for disposal? Horticultural Technology 3(1):70-73.

12 Garthe, J.W. and Kowal, P.D. 1993. Recycling used agricultural plastics. Agricultural and Biological Engineering Fact Sheet C-8. Penn State University. Available at Web site http://extension.psu.edu/pubs/c-8 (verified February 18, 2013).

13 Hayes, D.G., Dharmalingam, S., Wadsworth, L.C., Leonas, K.K., Miles, C., and Inglis, D.A. 2012. Biodegradable agricultural mulches derived from biopolymers. In K. Khemani and C. Scholz (eds). Degradable Polymers and Materials: Principles and Practice. 2nd ed. American Chemical Society, Washington, DC. p. 201-223.

14 ASTM D6400. 2004. International Standard Specification for Compostable Plastics. ASTM International, West Conshohocken, PA.

15 ASTM D883. 2011. International Standard Terminology Relating to Plastics. ASTM International, West Conshohocken, PA.

16 Briassoulis, D. and Dejean, C. 2010. Critical review of norms and standards for biodegradable agricultural plastics. Part I. Biodegradation in soil. Journal of Polymers and the Environment 18(3):384-400.

17 Anzalone, A., Cirujeda, A., Aibar, J., Pardo, G., and Zaragoza, C. 2010. Effect of biodegradable mulch materials on weed control in processing tomatoes. Weed Technology 24(3):369-377.

18 Miles, C., Klinger, E., Nelson, L., Smith, T., and Cross, C. 2007. Alternatives to Plastic Mulch in Vegetable Production Systems. Available at Web site http://vegetables.wsu.edu/ MulchReport07 (verified February 14, 2013).

19 Ngouajio, M., Auras, R., Fernandez, R.T., Rubino, M., Counts, J.W. and Kijchavengkul, T. 2008. Field performance of aliphatic-aromatic copolyester biodegradable mulch films in a fresh market tomato market system. Horticultural Technology 18(4):605-610.

20 Shogren, R.L. and David, M. 2006. Biodegradable paper/polymerized vegetable oil mulches for tomato and pepper production. Journal of Applied Horticulture 8(1): $12-14$.

21 Waterer, D. 2010. Evaluation of biodegradable mulches for production of warm season vegetable crops. Canadian Journal of Plant Science 90:737-743. 
22 Weber, C.A. 2003. Biodegradable mulch films for weed suppression in the establishment year of matted-row strawberries. Horticultural Technology 13(4):665-668.

23 Olsen, J.K. and Gounder, R.K. 2001. Alternatives to polyethylene mulch film - a field assessment of transported materials in capsicum (Capsicum annuum L.). Australian Journal of Experimental Agriculture 41(1):93-103.

24 Rangarajan, A. and Ingall, B. 2006. Biodegradable Mulch Product Testing 2006. Department of Horticulture, Cornell University. Available at Web site http://www.vegetables. cornell.edu/alt/Biodegradable $\% 20$ Mulch $\% 20$ Product $\%$ 20Testing\%2020063.pdf (verified March 4, 2013).

25 Schonbeck, M.W. 1998. Weed suppression and labor costs associated with organic, plastic, and paper mulches in small-scale vegetable production. Journal of Sustainable Agriculture 13(2):13-33.

26 Sorkin, L. 2006. New biodegradable mulch is cheaper than plastic when removal and disposal cost are also considered. Growing for Market 15(5):8-10.

27 Tullo, A.H. 2012. Old plastics, fresh dirt. Chemical and Engineering News 90(12):12-18.

28 Miles, C. and Marsh, T. 2012. Biodegradable plastic mulches: China, India and USA. In A. Tuinhof, F. Van Steenbergen, P. Vos, and L. Tolk (eds). Profit from Storage: The Costs and Benefits of Water Buffering. 3R Water Secretariat, Wageningen, The Netherlands. p. $80-84$.

29 Corbin, A., Cowan, J., Miles, C., Dorgan, J., and Inglis, D. 2013. Using Biodegradable Plastics as Agricultural Mulches. Washington State University Extension Fact Sheet FS103E. Available at Web site https://pubs.wsu.edu (verified February 4, 2013).

30 Agricultural Marketing Service. 2012. Final Recommendation: Biodegradable Mulch Film made from
Bioplastics (Passed). Available at Web site http://www.ams. usda.edu/AMSv1.0/getfile?dDocName=STELPRDC5101277 (verified February 19, 2013).

31 Rogers, E.M. 2003. Diffusion of Innovations. 5th ed. Free Press, New York.

32 Ryan, B. and Gross, N.C. 1943. The diffusion of hybrid seed corn in two Iowa communities. Rural Sociology 13:273-285.

33 Fliegel, F.C. 1993. Diffusion Research in Rural Sociology: The Record and Prospects for the Future. Greenwood Press, Westport, CT.

34 Fliegel, F.C. and Kivlin, J.E. 1966. Attributes of innovations as factors in diffusion. American Journal of Sociology 72 (3):235-248.

35 Fliegel, F.C. and Kivlin, J.E. 1967. Differential perceptions of innovations and rate of adoption. Rural Sociology 32(1):78-91.

36 Kremer, K.S., Carolan, M., Gasteyer, S., Tirmizi, S.N., Korsching, P.F., Peter, G., and Tong, P. 2001. Evolution of an agricultural innovation: The N-Trak soil nitrogen test-adopt and discontinue, or reject? Technology in Society 23(1):93-108.

37 Rogers, E.M. and Shoemaker, F.F. 1971. Communication of Innovations: A Cross-Cultural Approach. Free Press, New York.

38 Carolan, M. 2006. Do you see what I see? Examining the epistemic barriers to sustainable agriculture. Rural Sociology 71(2):232-260.

39 Dillman, D.A., Smyth, J.D., and Christian, L.M. 2009. Internet, Mail, and Mixed Mode Surveys: The Tailored Design Method. 3rd ed. Wiley, Hoboken, NJ.

40 North Central Rural Sociology Committee (NCRSC). 1962. How Farm People Accept New Ideas. Special Report No. 15. Cooperative Extension Service, Iowa State University, Ames, IA. 